\title{
Assessment of the Impact of Namibian Rural Road Characteristics on Crash Incidence
}

\author{
By Robert Ambunda* \& Petrina Johannes ${ }^{*}$
}

\begin{abstract}
Road user perceptions and roadway design elements play a vital role in determining the crash risk level on the roads. The study investigated factors that play a prominent role in causing road traffic crashes on rural roads on the Namibian road network. The study found that animals and pedestrians were the highest cause of road traffic crashes on the study sections. The high volume of vehicles traversing the roads section combined with the lack of appropriate barriers to separate traffic from the high presence of animals and pedestrians along the study section contributed to the hazardous safety situation on the road. The study identified that drivers losing control of vehicles on the study sections was one of the highest cause of traffic crashes. Speeding combined with negative design of various road elements directly impacts driver perceptions of the road environment and misleads road users, thereby leading to human errors that influence the frequency and severity of road crashes on the study section. The study identified under-reporting and misinformation on road crashes as some of the factors impeding the development of a vivid picture on the actual scale of the road safety problem on Namibian rural roads. The analysis of the road crashes will assist and enable road safety stakeholders in identifying, developing and implementing appropriate safety measures to sustainably address the road safety issue on Namibian roads. In addition to the road safety assessment, a road design audit carried out on the study section found that the shoulder grade and lane widths did not comply with the Technical Recommendations for Highways 17 on the Geometric Design of Rural Roads in Namibia. The study therefore developed multivariate road crash models using Negative Binomial Regression to investigate the extent of the link between road crash rates of various severity and the road design elements. The models identified several interactive relationships between lane widths, shoulders widths, $85^{\text {th }}$ operating speed and horizontal curve radii on the section that significantly influenced crash rates on the roads.
\end{abstract}

Keywords: Driver Behaviour, Road Crash Modelling, Road Design Elements, Road Safety, Rural Roads.

\section{Introduction}

The issue of providing a safe roadway environment within the rural road network is one of the fundamental principles governing engineering, traffic and transportation planning stakeholders. Gichaga (2017) describes road safety as the science of providing measures and methods that reduce the number of road crashes and injured road users involved in traffic crashes.

\footnotetext{
*Lecturer, University of Namibia, Namibia.

${ }^{\star}$ Senior Lecturer, University of Namibia, Namibia.
} 
Addressing road safety issues that relate to the three major traffic safety pillars; humans, vehicles and infrastructure, has been a crucial challenge for transportation engineers. An important aspect of road safety analysis is to locate hazardous road sections, to understand how the potential relationship between driver behaviour, driver perceptions and the road environment affects the safety of all road users.

Ambunda and Sinclair (2019) mention that road safety analysis can be useful in identifying road sections prone to high road crash rates and injury severities, while determining the factors significantly influencing the occurrence and frequency of road crashes. Information on factors significantly impacting road crash occurrence and frequency is vital for road safety stakeholders to identify appropriate remedial measures to combat and reduce the number of crashes and severity of injuries on the roadway. Road traffic safety is a multifaceted problem which encompasses numerous factors; human, vehicle and the road environment as shown in Figure 1.

Figure 1. Contributing Factors to Road Crashes

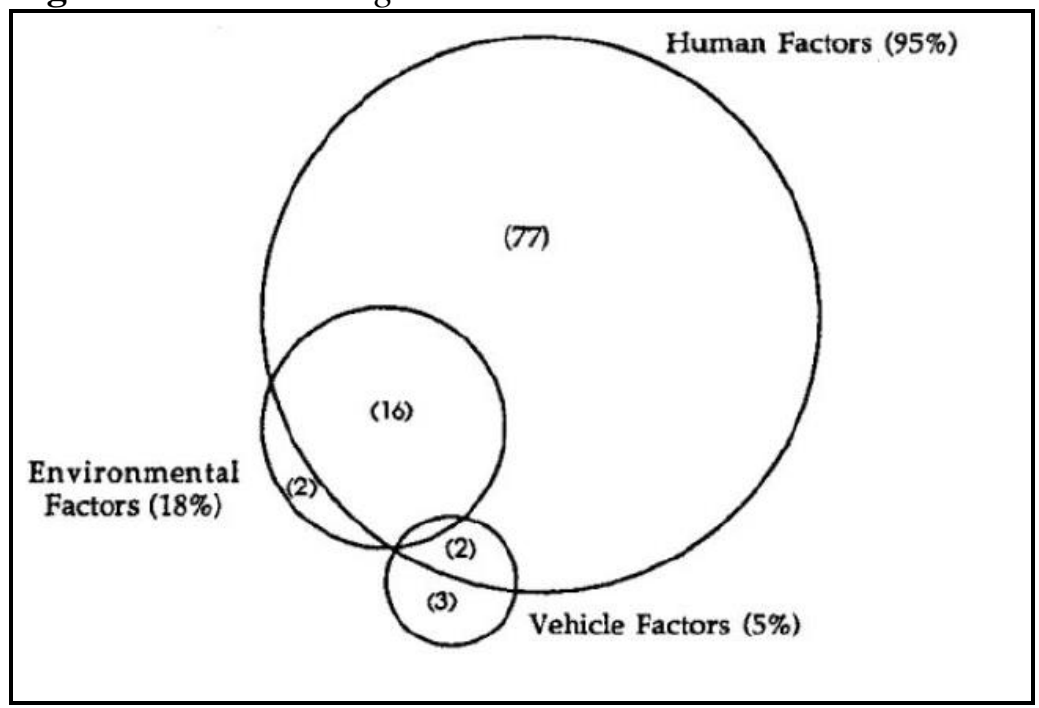

Source: Ambunda and Sinclair 2019.

Increased efforts in developing and enforcing traffic rules, educating road users on the importance of road safety and how perceptions are influenced by road design elements, coupled with improving the geometrical aspects of road infrastructure can positively influence traffic safety (Ambunda and Sinclair 2019).

The national rural road between Otjiwarongo and Okahandja (T0107) in Namibia, investigated in the paper was identified by Ambunda (2018) as one of ten national rural roads with the highest road crash rates, with an annual growth of $3.51 \%$ in road traffic volumes from 2011 (286,292 vehicles) to 2015 (374,710 vehicles). This paper examined the main causes of road crashes of various severity levels and carried out a road audit on T0107, through comprehensively analysing road crash data provided by the Namibian National Road Safety Council for the study period 2011 to 2015 . Moreover, the paper investigated the relationship between the design elements on the study section and road crash rates through road crash predictive models. 


\section{Background}

Road traffic crashes are a major socio-economic drawback for most developing countries (Ackaah and Salifu 2011). The World Health Organisation WHO (2018) reports that every year, about 1.2 million road crash fatalities, and between 20 and 50 million road crash injuries of various severities are reported globally, with Duivenvoorden (2010) affirming road safety as one of the most significant issues in modern society. Dehuri (2013) cautions that road crashes are forecasted to be the third largest contributor to the global burden of injury and disease by the year 2020 .

Despite the absolute number of road crashes and road fatality rates having steadied or declined in many high income countries in recent years, crash data suggests an increasing trend in the global epidemic of traffic injuries in most regions of the world (Peden et al. 2004). The WHO (2018) cautions that road crashes are forecasted to be the fifth leading contributor to mortalities globally by 2030, leading to an estimated 2.4 million road fatalities annually, mostly in developing countries, if current trends continue (Table 1).

Table 1. Leading Causes of Death in 2004 and in 2030

\begin{tabular}{|c|c|c|}
\hline Rank & Leading Cause (2004) & Leading Cause (2030) \\
\hline $\mathbf{1}$ & Ischaemic Heart Disease & Ischaemic Heart Disease \\
\hline $\mathbf{2}$ & Cerebrovascular Disease & Cerebrovascular Disease \\
\hline $\mathbf{3}$ & Lower Respiratory Infections & $\begin{array}{c}\text { Chronic Obstructive Pulmonary } \\
\text { Disease }\end{array}$ \\
\hline $\mathbf{4}$ & Chronic Obstructive Pulmonary & Lower Respiratory Infections \\
\hline $\mathbf{5}$ & Diarrease & Road Traffic injuries \\
\hline $\mathbf{6}$ & HIV/ AIDS & Trachea, Bronchus, Lung Cancers \\
\hline $\mathbf{7}$ & Tuberculosis & Diabetes Mellitus \\
\hline $\mathbf{8}$ & Trachea, Bronchus, Lung Cancers & Hypertensive Heart Disease \\
\hline $\mathbf{9}$ & Road Traffic injuries & Stomach Cancer \\
\hline $\mathbf{1 0}$ & Premature and Low Birth Weight & HIV/ AIDS \\
\hline
\end{tabular}

Source: https://www.who.int/healthinfo/global_burden_disease/GBD_report_2004update_part2.pdf.

Yannis et al. (2016) emphasise the importance of regular road safety assessments, as they are key to most countries addressing road safety problems. To enable countries to compare their road safety situation with other countries and to measure global progress, road safety assessments require a standardized methodology (Peden et al. 2004).

The safety of a roadway is influenced by an interplay of several factors and a combination various road design elements, which impact the perceptions and behaviour of drivers using the roadway (Dehuri 2013). Turner et al. (2015) state that, the ability of the roadway to communicate vital road information is important for drivers to be able to adjust and adopt their driving to road conditions, without risking the safety of other road users. In assessing the safety of roadway 
infrastructure, road crash modelling has been a useful instrument in identifying hazardous road sections, whilst investigating the extent of the influence of road design elements on road safety (Peter Hollo 2006).

With the increase in roadway traffic volume, traffic safety has become a serious concern in Namibia, with the Namibian National Road Safety Council NRSC (2012) reporting that the Namibian road injury fatality rate is higher than the African continental average by more than four fatalities per 100,000 population. The annual road fatality rate of 31 per 100,000 population translates to 600 to 700 fatalities in road crashes every year in Namibia (Namibia Statistics Agency - NSA 2015).

In Namibia, as reported by the Namibian Statistics Agency (2015), the number of road traffic crashes (RTC) per 100,000 population increased from 685.6 crashes in 2011 to 807.2 crashes in 2015 , this represented an annual average increase of $4 \%$ over the study period, as illustrated in Figure 2.

Figure 2. Road Traffic Crashes per 100,000 Population in Namibia between 2011 to 2015

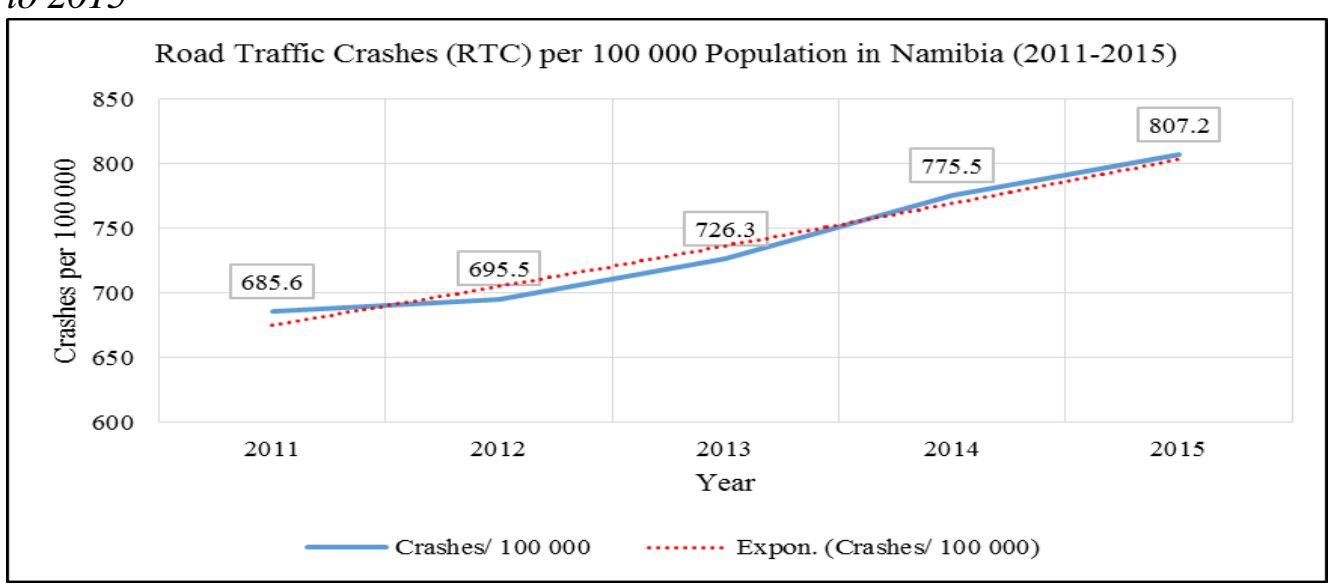

A similar increasing trend was observed in the road fatalities per 100,000 population for the past five years up until 2015 as shown in Figure 3, with an increase from 24.94 in 2011 to 31.22 in 2015 reported by the Namibian Statistics Agency (2015).

Figure 4 shows an increasing trend in the rate of road users injured in road crashes, from 267.8 in 2011 to 284.3 injuries per 100,000 population in 2015 , as reported by the Namibian Statistics Agency (2015).

In this paper, the historical road crash database for the section T0107 between Otjiwarongo and Okahandja was analysed and mapped using QGIS. Additionally, a road audit (cross-sectional audit) was also carried out to ensure the compliance of the study section with the road design standards used in Namibia. The crash data and road audit were used to understand the causes of road crashes on the study section. 
Figure 3. Road Fatalities per 100,000 Population in Namibia between 2011 to 2015

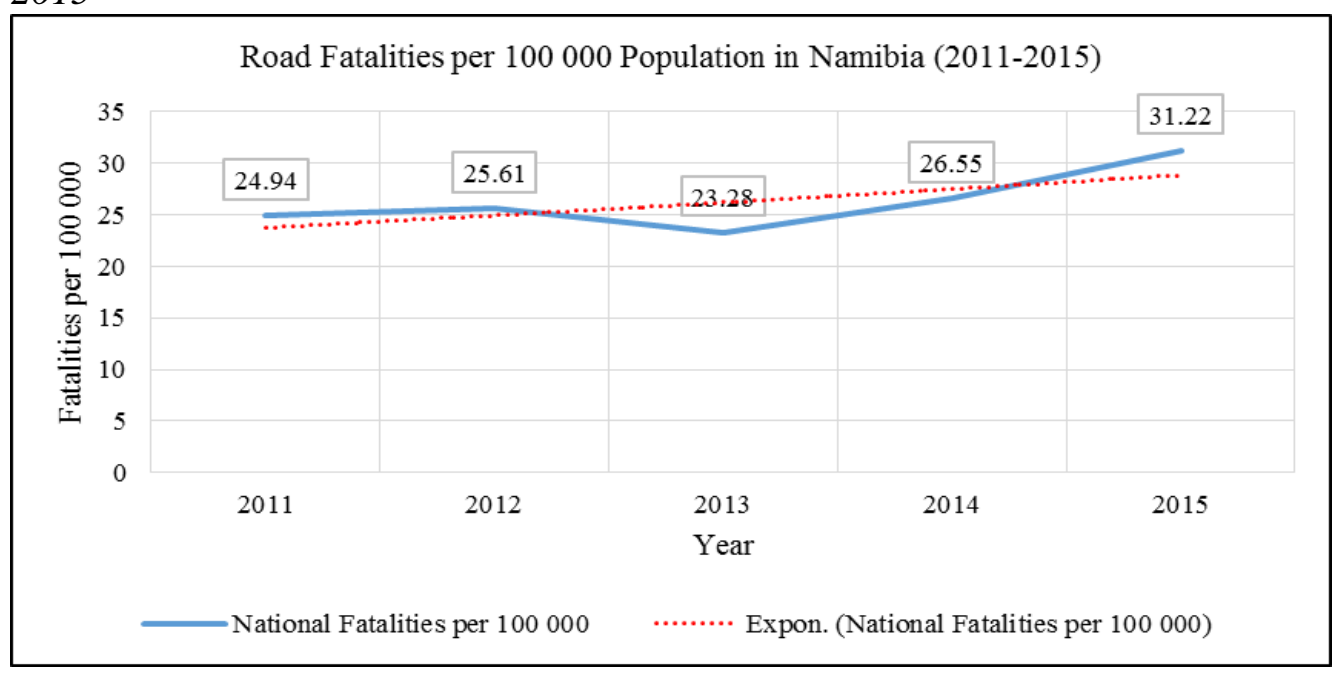

Figure 4. Road Injuries per 100,000 Population in Namibia between 2011 to 2015

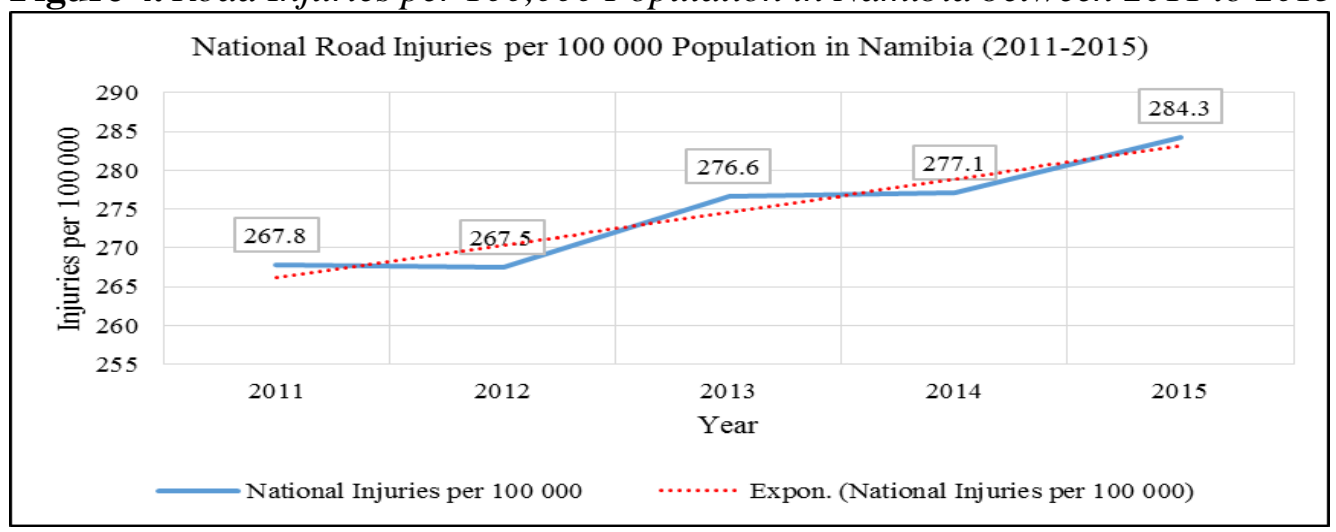

\section{Data and Method}

Data

Existing road crash data was collected from the Namibian National Road Safety Council (NRSC), considering data quality and availability from 2011 to 2015. To ensure that no inconsistencies arose across the data, it was vital to ensure that no remedial geometric work or upgrades were carried out on the study section during the analysis period 2011 to 2015 . The Technical Recommendations for Highways 17 (TRH 17) on the Geometric Design of Rural Roads (Committee of State Road Authorities - CSRA 1988a, b) was used to assess compliancy of the road section with design recommendations. Table 2 provides the recommendations for the study road section as a national rural road by the TRH 17. 
Table 2. TRH 17 Recommendations for the Study Section

\begin{tabular}{|c|c|}
\hline $\begin{array}{c}\text { Road Design Element } \\
\text { Horizontal curve radii (Min. curve } \\
\text { radii) }\end{array}$ & TRH 17 Recommendation \\
\hline Speed Limit & $530 \mathrm{~m}$ \\
\hline Lane width & $120 \mathrm{~km} / \mathrm{h}$ \\
\hline Shoulder Width & $3.5 \mathrm{~m}$ \\
\hline Number of lanes & $2.0 \mathrm{~m}$ \\
\hline Shoulder grade & 2 \\
\hline Lane grade & $4 \%$ \\
\hline
\end{tabular}

Source: CSRA 1988a, b.

The study section T0107 is a single carriageway surfaced with bitumen, with a posted speed limit of $120 \mathrm{~km} / \mathrm{h}$. The study section has 13 horizontal curves. The locations of the 13 horizontal curves are shown in Figure 5.

Figure 5. Horizontal Curve Location on Study Section

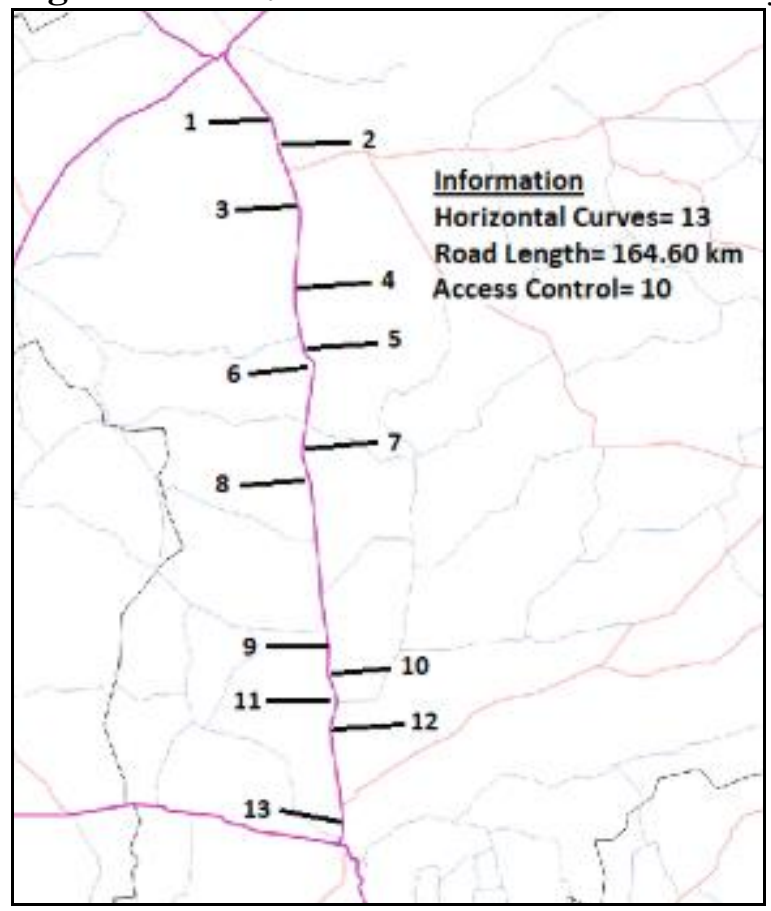

Table 3 shows the horizontal curve radii for the 13 curves on the study section. 
Table 3. Horizontal Curve Radii on the Study Section

\begin{tabular}{|c|c|}
\hline Horizontal curve & Curve radius (m) \\
\hline $\mathbf{1}$ & 1,850 \\
\hline $\mathbf{2}$ & 1,710 \\
\hline $\mathbf{3}$ & 2,900 \\
\hline $\mathbf{4}$ & 3,500 \\
\hline $\mathbf{5}$ & 1,717 \\
\hline $\mathbf{6}$ & 770 \\
\hline $\mathbf{7}$ & 1,126 \\
\hline $\mathbf{8}$ & 1,920 \\
\hline $\mathbf{9}$ & 2,300 \\
\hline $\mathbf{1 0}$ & 3,000 \\
\hline $\mathbf{1 1}$ & 1,400 \\
\hline $\mathbf{1 2}$ & 780 \\
\hline $\mathbf{1 3}$ & 2,200 \\
\hline
\end{tabular}

The road has a lane crossfall of $2.3 \%$ and a ground shoulder crossfall of $2.5 \%$. A combination of channelizing, dividing and no overtaking road markings are used on the road section. Figure 6 shows the cross-section design of the study sections.

Additional design information for section T0107 as collected from the road section is provided in Table 4.

Table 4. Road Design Information for Section T0107

\begin{tabular}{|c|c|}
\hline RL $(\mathrm{km})$ & 165 \\
\hline PSL $(\mathrm{km} / \mathrm{h})$ & 120 \\
\hline $85^{\text {th }}$ Percentile Traffic Speed $(\mathrm{km} / \mathrm{h})$ & 120.30 \\
\hline AADT (Bi-Directional) & 1,973 \\
\hline PT & B \\
\hline Lanes & 2 \\
\hline Lane Width (m) & 3.3 \\
\hline GSF (m) & 2.50 \\
\hline GSB (m) & 2.55 \\
\hline SSF (m) & 0 \\
\hline SSB (m) & 0 \\
\hline No. of HC & 13 \\
\hline AC & 10 \\
\hline
\end{tabular}

RL represents the length of the road section in km; PSL represents the Posted Speed Limit of the road section in $\mathrm{km} / \mathrm{h}$; PT represents the pavement type (B represents bitumen); GSF represents the width of the forward unsurfaced shoulder; GSB represents the width of the backward unsurfaced shoulder; SSF represents the width of the forward surfaced shoulder; SSB represents the width of the backward surfaced shoulder; HC represents the number of horizontal curves; AC represents the level of access control on the road section.

Figure 6 and Table 4 indicate that the study section was not fully compliant with the Technical Recommendations for Highways 17 (TRH 17) on the Geometric Design of Rural Roads (CSRA 1988a, b) with regard to shoulder crossfalls and lane widths. The study section complied with ground shoulder 
widths, lane crossfall, horizontal curve radii and the posted speed limits recommendations by TRH 17, influenced by the AADT and road classification.

Figure 6. Cross Section for Road Section T0107

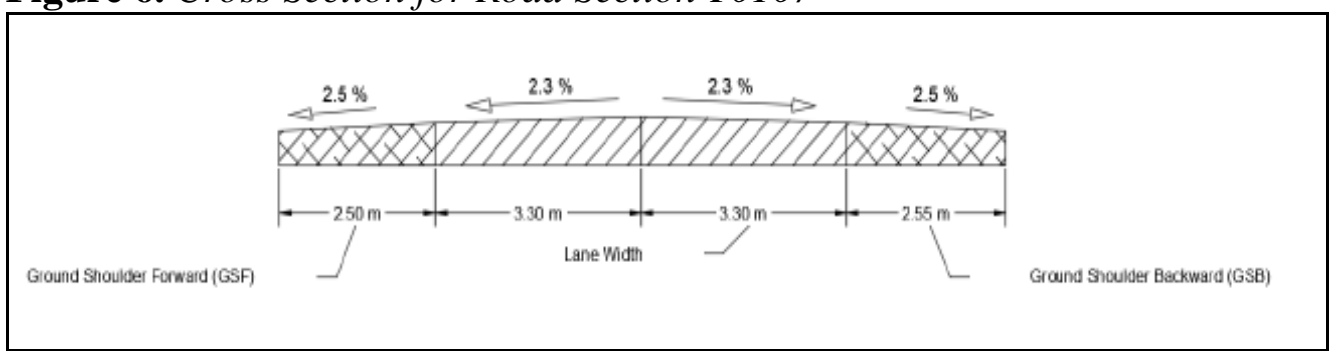

A total of 95950 traffic crash cases were collected nationally, with 711 road traffic crash cases observed on the identified national rural road during the selected five-year study period. Traffic information on the Annual Average Daily Traffic (AADT) was collected from the Road's Authority of Namibia for the study period under consideration.

\section{Method}

The two-lane two-way road between Otjiwarongo and Okahandja (T0107) with a road length of $165 \mathrm{~km}$ was identified as one of the ten most hazardous national rural roads on the Namibian road network. Three road sections on T0107 were identified (heat map rating $\geq 3.85$ ) for analysis using QGIS, with a bandwidth of $500 \mathrm{~m}$. Equation (1) was used to determine the crash rates for the identified study sections.

$C R=\frac{R T C \times 10^{6}}{A A D T \times 365 \times T \times L}$

Where: $\mathrm{CR}=$ Crashes per million vehicle kilometres travelled

RTC = A collision event involving a mechanically propelled vehicle involving an element of causality.

AADT $=$ Average Annual Daily Traffic

$\mathrm{L} \quad=$ Length of study sections $(\mathrm{km})$

$\mathrm{T}=$ Duration of study period (years)

$365=$ Number of days/ year

Table 5 provides road crash information on T0107 sections from Otjiwarongo to Okahandja. The majority of the RTCs occurred on Section 1 from Otjiwarongo, which represented $51.2 \%$ (311) of the total crashes during the study period. Section 2 recorded the second highest RTCs with $32.6 \%$ (198) of the total road crashes. $16.1 \%$ (98) of the total RTCs were recorded on Section 3 in the proximity of Okahandja. 
Table 5. Road Crash Information on the Study Section

\begin{tabular}{|c|c|c|c|}
\hline T0107 Sections & Road Length $(\mathbf{k m})$ & RTCs per section & $\begin{array}{c}\text { Crash } \\
\text { Rate }\end{array}$ \\
\hline Section 1 & 55 & 311 & 2.30 \\
\hline Section 2 & 46 & 198 & 1.68 \\
\hline Section 3 & 22 & 98 & 2.39 \\
\hline Total & 123 & 607 & \\
\hline
\end{tabular}

Figure 7 shows a heat map of the crashes on the Namibian national rural road network over the study period 2011-2015, with the study section T0107 encircled in red. A minimum average threshold of $5 \mathrm{~km}$ on the single carriageway from an urban setting is recommended as a starting point for road safety assessments on national rural roads (Joanne 2013).

Figure 7. Road Traffic Crashes in Namibia from 2011 to 2015

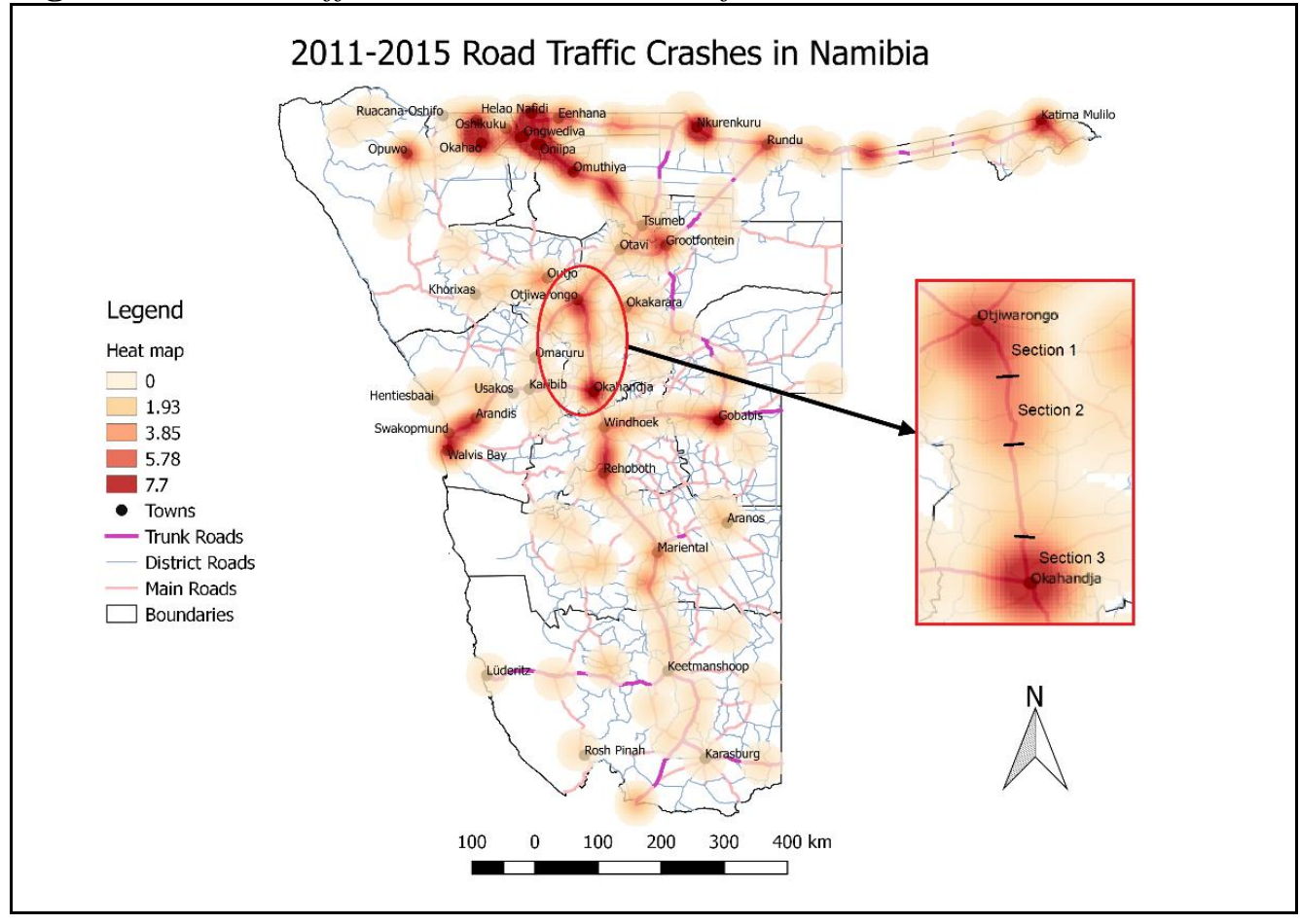

Individual mean differences were analysed using the Analysis of Variance (ANOVA) as shown in Table 6, to ascertain whether a statistically significant difference exists at $5 \%$ level $(\mathrm{p}<0.05)$ for the different crash rates determined. While the number of RTCs varied for the four road sections, the study sections crash rates determined were not found to be statistically different from each other $(\mathrm{p}=0.5>0.05)$. 
Table 6. Analysis of Variance (ANOVA) of the Crash Rates on the Study Sections

\begin{tabular}{|c|c|c|c|c|c|}
\hline \multicolumn{7}{|c|}{ ANOVA } \\
\hline & Sum of Squares & df & Mean Square & F & P (Sig). \\
\hline Between Groups & 0.000 & 2 & 0.000 & 1.500 & 0.500 \\
\hline Within Groups & 0.000 & 1 & 0.000 & & \\
\hline Total & 0.000 & 3 & & & \\
\hline
\end{tabular}

Using Negative Binomial Regression (Generalized Linear Models), the study developed multivariate road crash prediction models to assess the extent of the link between road crash rates determined by the study and the road design elements investigated in the road audit. The crash model consisted of the following three components (Oppong 2012):

1. A random component, which specifies the conditional distribution of the response variable, $Y_{i}$ given the exploratory variables, $x_{i j}$

2. A linear function of the regression variables, called the linear predictor,

$$
n_{i}=\propto+\beta_{1} X_{i 1}+\cdots+\beta_{k} X_{i 1}=x_{i}^{\prime} \beta
$$

The expected value $\mu_{i}$ of $Y_{i}$ depends on the linear predictor in the linear function.

3. An invertible link function,

$$
g\left(\mu_{i}\right)=\eta_{i}
$$

4. The invertible link function transforms the expectation of the response to the linear predictor. The inverse of the link function is sometimes called the mean function:

$$
g^{-1}\left(\eta_{i}\right)=\mu_{i}
$$

(4)

\section{Results and Discussion}

Road safety is a complex multidisciplinary global problem. The study showed that Namibia is faced with high crash rates, and the lack of or inadequate implementation of the following systems exacerbates the road safety issue:

I. The absence of appropriate road safety policies.

II. The lack of an efficient and reliable collision information management system. 
III. The lack of coherent traffic safety management strategies.

IV. The lack of consistent and aggressive road user education programmes.

\section{Crash Data Assessment}

A total of 607 of 711 road traffic crashes on T0107 were evaluated from the crash database provided by the NRSC during the study period 2011 to 2015. Figure 8 shows the classification and evaluation of the road crash causes on the study Section 1 to Section 3.

Figure 8. Road Traffic Crashes Causes on T0107 from 2011 to 2015

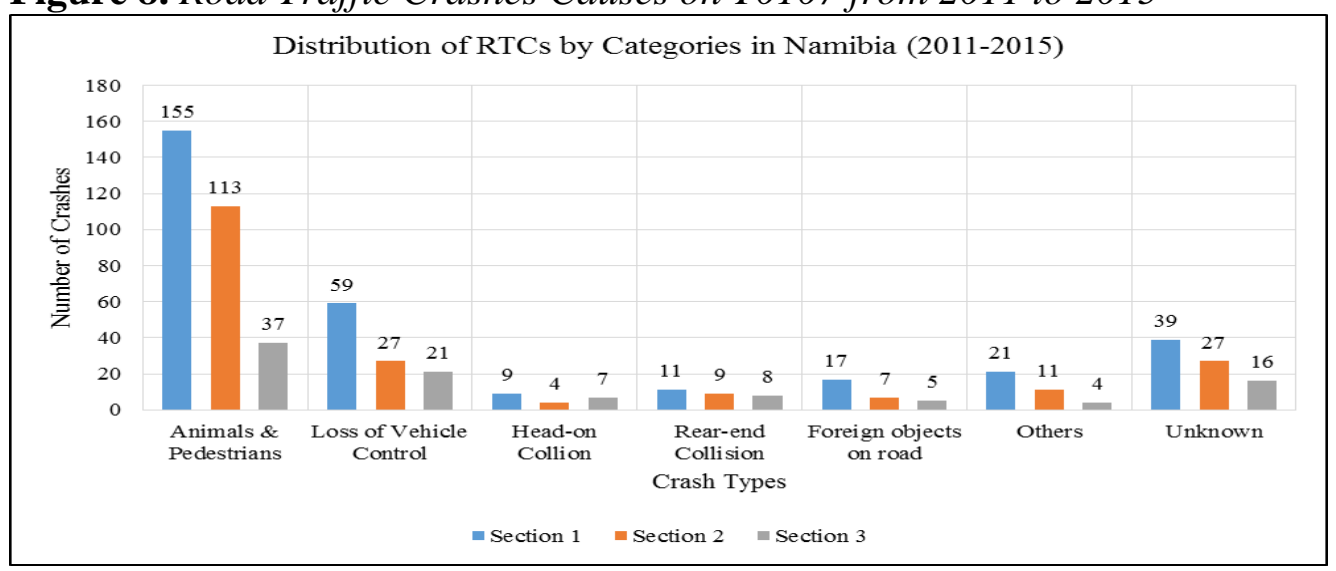

The study found that animals and pedestrians were the cause of the majority of RTCs on all the study sections, representing $49.8 \%, 57.1 \%$ and $37.8 \%$ of the crashes on Section 1, Section 2 and Section 3 respectively. In contrast, head on collisions were the least cause of traffic crashes on all the study sections, contributing less than $5 \%$ of all crashes on all Sections.

Drivers losing control of vehicles on the roads was the second highest contributor to RTCs on Sections 1 to Section 3, contributing 19\%, 13.6\% and $21.4 \%$ of all crashes on the study sections respectively. A study by Bamdad Mehrabani and Mirbaha (2018) found that drivers tend to be involved in single vehicle crashes as the road length increases.

RTCs reported as "Unknown" by the Namibian National Road Safety Council were the third highest contributor to crashes on all the study sections. Butchart and Mikton (2014) stress the importance of reliable and accurate data on RTCs in assessing the scope of the road crash problem, in order to target preventive measures, monitor and evaluate the effectiveness of the measures implemented. Lautrédou (2007) mentions that a huge gap remains in the coverage and quality of data countries collect and report on RTCs. This is particularly worrying that slightly less than $15 \%$ of all traffic crash causes on Section 1 and Section 2 and slightly more than $15 \%$ of crashes on Section 3 were reported as "Unknown".

Rear-end collisions constituted $3.5 \%$ of crashes on Section $1,4.5 \%$ on Section 2 and $8.2 \%$ on Section 3. RTCs caused by foreign objects on the road surface constituted less than $10 \%$ of crashes on Section 1 to Section 3, with $5.5 \%$, 3.5\% and $5.1 \%$ of all crashes respectively. RTCs caused by conditions categorized as 
"Other" constituted approximately $6.8 \%$ of crashes on Section 1 . The study also found that $5.6 \%$ and $4.1 \%$ of the crashes on Section 2 and Section 3 respectively were caused by conditions reported as "Other".

\section{Road Design Elements Assessment}

The design of the study sections was assessed for compliancy with road design standards (TRH 17 on the Geometric Design of Rural Roads) used to develop Namibian national rural roads. It was therefore vital in addition to the assessment of the crash data, to establish the extent of the link between the road crash rates (independent variables) and the road design elements (covariates).

The study developed multivariate crash prediction models that analysed the impact of the road design elements on road crash rates of various severity on the study section using Negative Binomial Regression methods. The study found that the simultaneous combinations of several road design covariates in the models were statistically significantly impacting the road crash rates at $95 \%$ confidence level.

The study found that the combination of lane widths (LW) and shoulder widths (SW) had a statistically significant $(\mathrm{p}=0.000<0.05)$ impact on the crash rates, accounting for $84.1 \%$ of the variance in the crash rates, with the NBR model indicating a negative significant correlation of $\mathrm{B}=-13.2577$ between lane widths and the crash rates on the study sections.

The interactive relationship between lane widths, $85^{\text {th }}$ percentile operating speed (OpSpeed) and shoulder widths, statistically significantly $(\mathrm{p}=0.000<0.05)$ accounted for $87.3 \%$ of the variance in the crash rates, with the lane width and $85^{\text {th }}$ percentile speed showing significant correlations of $\mathrm{B}=-3.254$ and $\mathrm{B}=0.341$ respectively.

The combination of horizontal curve radii (HCRAD) and road length had a significant influence $(p=0.0024<0.05)$ on crash rates, accounting for $75.4 \%$ of the variance in crash rates on the study section. Despite the interactive relationship between the covariates, the NBR model developed found that only the horizontal curve radii on the study section had a significant correlation of $\mathrm{B}=-1.2454$ on crash rates on the study section.

Table 7 shows the results of the interactive relationships between covariates on crash rates (fatal, serious, slight and damage only) as identified by the NBR models developed.

Table 7. Multivariate Road Crash Model Information

\begin{tabular}{|c|c|c|c|c|c|}
\hline Covariates & $\begin{array}{c}\text { Model P } \\
\text { value }\end{array}$ & $\begin{array}{c}\text { Model } \\
\text { Adjusted } \\
\mathbf{R}^{\mathbf{2}}\end{array}$ & $\begin{array}{c}\text { Significant } \\
\text { model variable }\end{array}$ & $\begin{array}{c}\text { Variable P } \\
\text { value }\end{array}$ & $\begin{array}{c}\text { Variable B } \\
\text { value }\end{array}$ \\
\hline LW \& SW & 0.0000 & 0.8411 & $\mathrm{LW}$ & 0.0002 & -13.2577. \\
\hline $\begin{array}{c}\text { LW, } \\
\text { OpSpeed \& } \\
\text { SW }\end{array}$ & 0.0000 & 0.8732 & $\mathrm{LW}$ & 0.0012 & -5.7231 \\
\hline $\begin{array}{c}\text { HCRAD \& } \\
\text { road length }\end{array}$ & 0.0023 & 0.7547 & HCRAD & 0.0020 & -1.2454 \\
\hline
\end{tabular}




\section{Conclusions}

\section{Crash Data Assessment}

The study examined and carried out a road traffic crash assessment on the road T0107 between Otjiwarongo and Okahandja on the Namibian rural road network.

The study identified three road sections on T0107 for investigation from Otjiwarongo towards Okahandja; Section 1 starts $5 \mathrm{~km}$ from Otjiwarongo and spanning a distance of $55 \mathrm{~km}(60 \mathrm{~km}$ marker), Section 2 spans a distance of $46 \mathrm{kms}$ from the $60 \mathrm{~km}$ marker. Section 3 starts $5 \mathrm{~km}$ from Okahandja and spans a distance of $22 \mathrm{~km}$.

The majority of the road traffic crashes were found to have occurred on Section 1 on T0107, which is much closer to the town of Otjiwarongo and had the longest distance $(55 \mathrm{~km})$ investigated, whereas the least number of crashes occurred on Section 3 in the proximity of Okahandja, with the highest crash intensity on the heat map and the shortest distance $(22 \mathrm{~km})$ investigated.

The study found that the majority of road traffic crashes on the study sections on T0107 were caused by the presence of animals and pedestrians on the roads. The Non-Motorised Users were the cause of approximately half of the crashes on Section 1 and slightly less than three fifths and two fifths on Section 2 and Section 3 respectively. The study sections have a precarious history of wild and domestic animals being stranded on the road and the chances of drivers hitting one of them are immense. The study identified, head on collisions were found to be the least cause of crashes on all road sections investigated.

The study found that approximately a sixth of the road traffic crashes on the study sections were reported as "unknown" due to under-reporting. Underreporting hampers road safety stakeholders in providing a vivid picture of the magnitude of the road safety issue. Furthermore, the multiplicity of the different information that is recorded on road crashes hardens the task of making exact comparisons of road safety situations between multiple institutions and countries.

\section{Road Design Elements Assessment}

The Negative Binomial Regression models developed by the study investigated the extent of the relationship between road design elements on the study section and the crash rates (All severities and damage only).

The study found that the interaction between lane widths and shoulder widths had a statistically significant influence on road crash rates on the study section, with the lane width variable showing a significant negative correlation on road crash rates with every one unit increase in the variable reducing the log count of road crashes.

The interactive relationship between lane width, $85^{\text {th }}$ percentile operating speeds and shoulder width was found to significantly influence crash rates, with significant correlation between the crash rates, lane widths and operating speeds 
on the study section. Also, the study found that road hard shoulder widths and types on the section did not significantly impact the crash rates.

The study findings demonstrated that the interaction between the horizontal curve radii and road length was significant in influencing crash rates on the study section, with one unit increase in the horizontal curve radii indicating a significant negative log count in the crash rates. An inverse relationship was found to exist between crash risk levels and the horizontal curve radii, with a radius considered critical at radii less than $350 \mathrm{~m}$.

The study has demonstrated that significant multivariate correlations exist between road design elements and crash rates on the study section. The study has also shown that further investigations into the causation factors that impact the influence crash risk level on undivided rural roads and the crash data collection methods used by the road safety authorities, especially with the high percentage of crashes recorded as "unknown". Moreover, the study has indicated that an investigation into the feasibility of Non-Motorised Users infrastructure and safety barriers on the study section is necessary for the safety of the section.

\section{Acknowledgments}

Our thanks to the Faculty of Engineering and Information Technology at the University of Namibia, for the valuable support throughout the study. The Namibian Road Safety Council and the Roads Authority of Namibia are acknowledged for their assistance with crash and road characteristic data collection.

\section{References}

Ackaah W, Salifu M (2011) Crash prediction model for two-lane rural highways in the Ashanti region of Ghana IATSS Research. International Association of Traffic and Safety Sciences 35(1): 34-40.

Ambunda R (2018) Analysis of the relationship between fatal rural road crashes and road design elements: Namibian case study. South Africa: Stellenbosch University.

Ambunda R, Sinclair M (2019) Effect of two-lane two-way rural roadway design elements on road safety. International Journal of Innovative Technology and Exploring Engineering 8(4): 632-637.

Bamdad Mehrabani B, Mirbaha B (2018) Evaluating the relationship between operating speed and collision frequency of rural multilane highways based on geometric and roadside features. Civil Engineering Journal 4(3): 609.

Butchart A, Mikton C (2014) Global status report on violence prevention 2014. Geneva, Switzerland.

Committee of State Road Authorities (1988a) Road classification and access management. In Technical Recommendations for Highways, TRH 26. Pretoria, South Africa: Department of Transport.

Committee of State Road Authorities (1988b) Geometric design of rural roads. In Technical Recommendations for Highways, TRH 17. Pretoria, South Africa: Department of Transport.

Dehuri AN (2013) Impacts of roadway condition, traffic and manmade features on road 
safety. Master Thesis. Rourkela, India: National Institute of Technology.

Duivenvoorden K (2010) The relationship between traffic volume and road safety on the secondary rural road network. Leidschendam: SWOV Institute for Road Safety Research.

Gichaga FJ (2017) The impact of road improvements on road safety and related characteristics. IATSS Research 40(2): 72-75.

Joanne M (2013) RAP road risk mapping manual: design specification. Brussels: European Road Assessment Programme (EuroRAP).

Lautrédou G (2007) Practical guide on road safety: a toolkit for national red cross and red crescent societies. Switzerland: International Federation of Red Cross and Red Crescent Societies.

Namibia National Road Safety Council (2012) Road accidents in Namibia statistical report 2012. Windhoek. Doi: 10.1017/CBO9781107415324.004.

Namibia Statistics Agency (2015) Namibia social statistics 2010-2015. Windhoek.

Oppong RA (2012) Statistical analysis of road accidents fatality in ghana using poisson regression. Thesis. Ghana: Department of Mathematics, Kwame Nkrumah University of Science and Technology.

Peden M et al. (2004) World report on road traffic injury prevention. International Journal of Injury Control and Safety Promotion 12(2).

Peter Hollo HD (2006) Methods and examples of road accident data analysis. Improving the Safety of Road Infrastructure International Seminar and Workshop AGEPAR/ PIARC Togo, Lomé $11^{\text {th }}-13^{\text {th }}$ October 2006. Available at: https://bit.ly/2pF4uDh.

Turner B, Woolley J, Cairney P (2015) An analysis of driver behaviour through rural curves: exploratory results on driver speed. Journal of the Australasian College of Road Safety 26(4): 31-37.

WHO (2018) Global Status Report on Road Safety. Switzerland: World Health Organisation.

Yannis G et al. (2016) Use of accident prediction models in road safety management - an international inquiry. Warsaw: $6^{\text {th }}$ Transport Research Arena. 
